The Canadian Society for Bioengineering

The Canadian society for engineering in agricultural,

food, environmental, and biological systems.

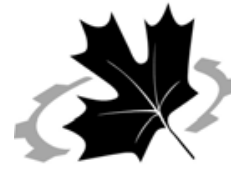

La Société Canadienne de Génie Agroalimentaire et de Bioingénierie La société canadienne de génie agroalimentaire, de la bioingénierie et de l'environnement

CSBE $\mid S C G A B$

Paper No. 06-112

\title{
The Development of a Dynamic Flux Chamber System for the Collection of Gaseous Emissions During On-Farm Composting of Animal Mortalities.
}

\section{P.J. Linton}

Department of Engineering, University of Guelph, Guelph, Ontario, Canada, N1G 2W1.

\section{B.J. Van Heyst}

Department of Engineering, University of Guelph, Guelph, Ontario, Canada, N1G 2W1.

\author{
Written for presentation at the \\ CSBE/SCGAB 2006 Annual Conference \\ Edmonton Alberta \\ July 16 - 19, 2006
}

\begin{abstract}
The interest in on-farm composting of animal mortalities (deadstock) has emerged over the past decade due to increasing rendering costs and biosecurity issues posed by traditional deadstock collectors. Although composting is a widely accepted method of deadstock disposal there has been few studies performed on the environmental impacts associated with the process, particularly the atmospheric emission of compost gases. A preliminary methodology for characterizing emissions from deadstock composting has been developed. A state of the science compost facility has been constructed to perform species-specific bin composting trials in a semi-controlled environment. To obtain a representative emission sample, a dynamic flux chamber has been developed to enclose an entire bin and supply a constant airflow across the compost pile. Integrated air samples were collected over an hour period from the exhaust of the flux chamber and analyzed for $\mathrm{CO}_{2}, \mathrm{CH}_{4}$ /non-methane VOCs, $\mathrm{NH}_{3} / \mathrm{NO}_{2} / \mathrm{NO}$, and $\mathrm{SO}_{2}$. A series of tests have been performed to analyze the performance of the dynamic flux system. Recovery tests using $\mathrm{SO}_{2}$ as a trace gas have yielded values up to $91.9 \%$. Steady readings were usually achieved within 5 minutes of sampling. Further testing is required to fully evaluate the system's performance. Once the design of the methodology is complete long-term compost emission studies can be performed resulting in the development of composting emission factors.
\end{abstract}




\section{INTRODUCTION}

Over the past decade on-farm composting has emerged as a viable disposal method for animal mortalities (deadstock). The interest of deadstock disposal has increased due to biosecurity concerns, and escalating costs and stringency associated with pick-up for rendering. Options for deadstock disposal in Ontario are limited to rendering, composting and burial. Current regulations regarding burial are under review and may be removed in the future as a disposal option. Composting can be an excellent disposal method for deadstock if performed in a proper manner. However, if performed improperly, it can pose the risk of releasing contaminated leachate, attracting scavengers (that can potentially spread disease), and emitting offensive odours. Also, there are a variety of emissions released during the composting process that need to be characterized to evaluate their impacts on the environment as well as the nutrient availability in the finished compost.

There have been many emission studies performed on manure compost and municipal solid waste (MSW) compost. Under ideal aerobic conditions the gaseous emissions from the compost process are $\mathrm{CO}_{2}$ and water vapour. In actuality, gaseous emissions from compost are usually more complex containing mixtures of many undesirable compounds. Greenhouse gas (GHG) emissions, including $\mathrm{CH}_{4}, \mathrm{~N}_{2} \mathrm{O}$ and $\mathrm{CO}_{2}$, have been reported from composting manure (Amon et al. 2001; Hao et al. 2001; Kudora 1996; Paillat et al. 2005; Sommer and Moller 2000; Thompson et al. 2004). Methane production occurs under anaerobic conditions but may be oxidized to $\mathrm{CO}_{2}$ in aerobic zones near the surface of the compost. Sommer and Moller (2000) report 191.6 g-C/tonne of $\mathrm{CH}_{4}$ emitted from a manure/straw mixture over four months of composting. 
The study did not detect significant $\mathrm{CH}_{4}$ emissions until the concentration within the pile was greater than 500ppm suggesting a high oxidation rate of $\mathrm{CH}_{4}$. Similar findings by Hao et al. (2001) showed that $\mathrm{CH}_{4}$ concentrations were low near the surface but increased with depth. Also, studies have shown that most of the methane production occurs in the early stages of composting (Paillat et al. 2005; Hao et al. 2004). Nitrous oxide is typically emitted in much lower quantities than $\mathrm{CO}_{2}$ or $\mathrm{CH}_{4}$. Hao et al (2004) measured $0.1103 \mathrm{~g} / \mathrm{m}^{2} /$ day emitted as $\mathrm{N}_{2} \mathrm{O}$ compared to 0.239 and $0.0123 \mathrm{~kg} / \mathrm{m}^{2} /$ day of $\mathrm{CO}_{2}$ and $\mathrm{CH}_{4}$ respectively for manure and straw bedding compost. Although the emission rate is generally much less for $\mathrm{N}_{2} \mathrm{O}$ than the other GHGs, the warming potential for $\mathrm{N}_{2} \mathrm{O}$ is 310 times higher than that of $\mathrm{CO}_{2}$ (Draper 2002).

The primary source of volatile nitrogen losses during composting is ammonia $\left(\mathrm{NH}_{3}\right)$. Ammonia is an odourous compound that, on top of being a source of nutrient loss, causes soil and water acidification and contributes to the formation of secondary aerosols in the atmosphere. Beck-Friis et al. (2001) report that $\mathrm{NH}_{3}$ losses account for more than $98 \%$ of the total gaseous nitrogen loss in MSW compost. Generally $\mathrm{NH}_{3}$ emissions correlate to temperature profiles and nitrogen content, tending to increase as the pile temperature increases (Beck-Friis et al. 2001; Kuroda et al. 1996; Martins and Dews 1992; Paillat et al. 2005; Smet et al. 1999) and with higher nitrogen contents (Noble and Gaze 1995; Martins and Dews 1992). In addition to increasing pile temperatures and nitrogen content, ammonia emissions seem to depend on seasonal variations, due to the increasing moisture content mainly caused by snow melt (Amon et al. 2001; Parkinson et al. 2004). For example, Amon et al. (2001) reported ammonia 
emissions at 670.5 and $302.6 \mathrm{~g} /$ tonne of fresh matter for summer and winter periods respectively.

The majority of compost emissions data found in the literature focuses on GHGs and nitrogen losses by gaseous $\mathrm{NH}_{3}$. Odourous compounds such as reduced sulfurs and volatile organic compounds (VOCs) from composting have been less studied. A variety of VOCs have been detected from composting green waste and MSW but little attention has been given for the emission of VOCs from manure composting. Moreover, compounds such as nitrogen oxides $\left(\mathrm{NO}_{\mathrm{x}}\right)$ and sulfur dioxide $\left(\mathrm{SO}_{2}\right)$ have not been well characterized for compost applications.

Even though many studies report air emissions from a variety of compost applications, there are no known studies reporting emissions during deadstock composting, which is inherently heterogeneous in terms of pile makeup. Characterizing the air emissions from deadstock composting will assist in the development of best management practices (BMPs) and provide additional information to improve agricultural emission inventories.

Developing compost emission factors is not an easy task, as there are no set methodologies for characterizing emissions from compost piles. The method may differ depending on the compost recipe and the style of composting used (i.e. windrow, static pile, bin, compost plant, forced aeration etc.). The scope of this paper will focus on the development of a methodology to accurately characterize air emissions released during species-specific deadstock composting. The methodology will allow for the development of species-specific emission factors to aid in BMPs and agricultural emission inventories. The targeted compounds in this study include $\mathrm{NH}_{3}, \mathrm{NO}_{\mathrm{x}}, \mathrm{CH}_{4}$, non-methane 
hydrocarbons (NMHCs), $\mathrm{SO}_{2}$ and $\mathrm{CO}_{2}$. Preliminary results for the emission characterization methodology and the status of the composting trials are summarized.

\section{MATERIALS \& METHODS}

\section{Site description}

All compost trials are being conducted in a new state of the science compost facility located on the Elora Research Station (ERS) of the University of Guelph. The compost facility is a $25.6 \times 12.2$ meter concrete pad enclosed by $2.74 \mathrm{~m}$ high concrete walls. A Coverall ${ }^{\mathrm{TM}}$ fabric roof structure provides a semi-controlled environment, mainly to avoid the effects of wind, rain and snow. Inside, the facility is equipped with 12 concrete bins $(2.5 \times 2.5 \times 2.5 \mathrm{~m})$ for performing compost trials. Each bin has a $0.102 \mathrm{~m}$ diameter ventilation hole in the building wall $0.15 \mathrm{~m}$ from the top of the bin wall. The ventilation hole allows for a fresh exchange of ambient air when sampling for gaseous emissions. All sampling equipment is stored in a temperature and humidity-controlled laboratory (3 $\mathrm{x} 4.3 \mathrm{~m}$ ) constructed inside the compost facility. The purpose of the laboratory is to provide a clean, standard temperature and humidity environment in which the equipment can operate year round.

\section{Compost trials}

Deadstock compost trials commenced on November $20^{\text {th }}, 2005$, with $790 \mathrm{~kg}$ of swine mortalities. The procedure for building the compost heap was similar to that described by Keener et al. (2000) and Morse (2001). A $0.61 \mathrm{~m}$ base of a woodchip bulking agent was placed in the bin prior to any deadstock. Animal mortalities were then placed on top 
of the base layer. The carcasses were kept approximately $0.30 \mathrm{~m}$ away from the bin walls at all times. Some space was left between the carcasses to allow sufficient air circulation and reduce localized anaerobic pockets (Glanville 1999; Morse 2001). The carbonbulking agent was then placed over the carcasses to a depth of approximately $0.20 \mathrm{~m}$. Additional layers of carcasses and bulking agent were alternated as shown in Fig. 1. After the final layer of carcass was added the pile was capped with $0.61 \mathrm{~m}$ of bulking agent to provide insulation and a good biofilter for odour reduction purposes. Five additional compost trials have been initiated with swine, poultry and companion animal mortalities. A list of the compost trials and the initial properties is provided in Table 1. Temperatures, from thermocouples placed in the pile at three different heights during construction, were used to monitor the activity of the microorganisms. Mechanical turning to reintroduce air into the piles was performed once the pile temperatures drop steadily below $48^{\circ} \mathrm{C}$ (Koebel et al. 2003).

\section{Design of the dynamic flux chamber}

Emission measurements using the flux chamber method are typically classified as static or dynamic. Static chambers allow emissions to build up inside the chamber and a time weighted average is used to determine the emission flux. However, as the concentration builds up the flux is impeded due to the change in concentration gradient according to Fick's law (Hartman 2003). Guenther et al. (2000) reported that static type chambers used in a variety of studies changed the normal environmental conditions of the setting. For these reasons, the dynamic chamber approach was chosen for emission flux 
determination. Dynamic chambers allow for a constant internal volume exchange by drawing ambient air or forcing an inert sweep gas through the chamber.

The chamber shown in Fig. 2 was constructed to enclose an entire compost bin. Deadstock compost piles are not homogeneous mixtures, particularly in the primary stages, and therefore measuring the flux over the entire pile reduces the bias of localized emission pockets.

The chamber frame was constructed out of mild steel with polyethylene sheets enclosing the top frame and Plexiglas enclosing the front frame to allow visual inspection during emission sampling. Rubber garage door seals and weather stripping were placed around the edges of the frame to provide a seal and prevent contamination from adjacent bins. Three adjustable wheel jacks support the base of the chamber to account for minor differences in bin dimensions and to allow the flux chamber to easily roll from one bin to another. During sampling periods ambient air was allowed to enter the chamber through a $0.102 \mathrm{~m}$ diameter aluminum flex tube connected to a hole at the rear of the bin. A diffuser on the front of the chamber funneled the air from a $1.5 \times 0.61 \mathrm{~m}$ area down to a $0.102 \mathrm{~m}$ diameter exhaust pipe. Air was drawn across the pile and through the diffuser using a ventilation blower attached to the exhaust pipe. Flows were measured using a monometer and a flow damper that allowed the flow to vary between 55 and $170 \mathrm{~m}^{3} / \mathrm{h}$. Corresponding velocities ranged from 0.005 to $0.042 \mathrm{~m} / \mathrm{s}$ across the pile depending on the volume of headspace available. Emissions were drawn from a $14.7 \mathrm{~mm}$ stainless steel (SS) probe equipped with a 5 micron sintered SS filter, which was inserted in the exhaust pipe downstream of the blower. The location of the probe was selected downstream of the blower to allow for higher turbulence and mixing of the sample gas. 


\section{Emission sampling and data acquisition}

All data recording instrumentation was located in the temperature and humidity controlled laboratory on-site. Internal temperatures were maintained between 22 and $25^{\circ} \mathrm{C}$ and air was dehumidified to provide optimal conditions for the data acquisition equipment.

Pile temperatures. The temperature of each bin was monitored throughout the entire compost process using three type-T thermocouples (Copper-Constantan) per bin. Each thermocouple was placed at different depths within the pile (on the bottom layer, in the approximate middle, and on the top layer of carcasses) and horizontally in the center of the pile. All thermocouple wires were 24 gage Copper-Constantan. Temperatures were recorded every 60 seconds and averaged over an hour period by an AM16/32 multiplexer and 21X data logger from Campbell Scientific. A second 21X recorded the temperature and relative humidity inside the compost facility using Campbell Scientific's HMP50 Temperature/RH probe.

Sample collection. Samples were drawn from the SS probe through a $30.5 \mathrm{~m}$ heated Teflon ${ }^{\circledR}$ sample line at $115^{\circ} \mathrm{C}$ to ensure that no condensation occurred. Any condensation within the line could remove compounds such as $\mathrm{NH}_{3}$ from the sample jeopardizing the validity of the data. A KNF Teflon ${ }^{\circledR}$ coated diaphragm pump drew the sample at a flow rate of $8-10 \mathrm{~L} / \mathrm{min}$ and exhausted the sample outside of the laboratory. A 4 port manifold system attached to the line allowed the various analyzers to extract 
samples at a lower flow rate. Four three-way SS ball valves allowed the option of switching the analyzers between sampling from the flux chamber and outdoor air. Figure 3 shows a process control diagram of the sample collection and analysis system.

Sample analysis. Samples were analyzed using four continuous emission monitors analyzers from Thermo Electron Corporation (TEC). Carbon dioxide was measured using the Model $41 \mathrm{i}$ infrared absorption analyzer; $\mathrm{SO}_{2}$ was measured using the Model $43 \mathrm{C}$ florescence spectrum analyzer; $\mathrm{NH}_{3}, \mathrm{NO}$ and $\mathrm{NO}_{2}$ were measured with the Model $17 \mathrm{C}$ chemiluminescence analyzer; and $\mathrm{CH}_{4}$ and non-methane hydrocarbons (NMHCs) were measured using the model $55 \mathrm{C}$ gas chromatography with a flame ionization detector (FID). Properties of the four analyzers used are listed in Table 2.

Samples were drawn for a period of 30 to 60 minutes from each bin while being run through the system of analyzers. The analyzers logged data points every 10 seconds using a moving average from 1 to 300 seconds defined by the user. Output values were stored every 60 seconds and downloaded to a spreadsheet. The average concentrations over the entire sampling period were used to report single values. Air emissions were collected from an empty bin each day of sampling to account for background concentrations. The emission rate of each compound was estimated by:

$$
E_{x}=\left(C_{x}-C_{b}\right) \times Q
$$

Where $E_{x}$ is the emission rate of compound $x(\mathrm{~g} / \mathrm{h}), C_{x}$ is the average concentration of compound $x$ for the duration of the sampling period $\left(\mathrm{g} / \mathrm{m}^{3}\right), C_{b}$ is the background concentration measured from an empty bin $\left(\mathrm{g} / \mathrm{m}^{3}\right)$, and Q is the flow rate of the exhaust 
stream from the flux chamber $\left(\mathrm{m}^{3} / \mathrm{h}\right)$. All emission rates were corrected to $25^{\circ} \mathrm{C}$ and 1 atmosphere pressure.

\section{Quality assurance and control}

A quality assurance/quality control (QA/QC) management plan was implemented to validate the collected data. Standard operating procedures (SOPs) and control forms were developed to ensure consistency and monitor the performance of the entire data collection and analysis train. Analyzers were periodically calibrated depending on the amount of zero or span drift that had occurred. Zero and span drift checks and calibrations were performed using a zero air generator and calibration gases traceable to the National Institute of Standards and Technology (NIST). Two point calibrations were performed if the span concentration drifted more than 5\%. Once the span drifted more than $20 \%$ from the original calibration or major maintenance was conducted on the analyzer, a multipoint calibration was performed to ensure the linearity of the analyzer. A gas dilution system consisting of a manifold and four mass flow controllers was used to dilute the span gas for the multipoint calibrations.

The sample lines were flushed with ultra-pure zero air before and after each sampling period. Lines were flushed for approximately 10 minutes to purge any contaminants that may have remained. Leak tests were performed on a weekly basis to ensure no contamination from surrounding air occurred. Each fitting or connection that had potential to leak was temporarily pressurized and wetted with Snoop ${ }^{\circledR}$ leak tester. Leaks were identified visibly when the Snoop ${ }^{\circledR}$ bubbled. Detected leaks were repaired appropriately by tightening fittings. Finally, to report emission rates, at least 30 data 
points were collected for each sampling period and a statistical analysis testing the normal distribution of data was used to develop a representative value.

\section{Dynamic flux chamber performance tests}

A series of tests were conducted to determine the flow patterns within the dynamic flux chamber and the sensitivity of the analyzers under different operating conditions. These tests were used to evaluate the performance of the designed flux chamber. The following tests were performed:

Leak Test. In order to ensure that the flux chamber maintained a good seal, preventing contamination from adjacent bins, a leak test was performed. Smoke was blown around the outside of the chamber at all possible leak locations. At the same time the blower was set to the maximum flow rate to mimic the worst-case scenario for leaks. Leaks were detected by visual inspection of smoke entering the chamber. Repairs were made as necessary.

Flow Pattern Test. Initial evaluation of the flow field within the flux chamber was performed using a fog generator. Fog was introduced through the $0.102 \mathrm{~m}$ diameter vent at the rear of the flux chamber. Visual observations were made from inside the flux chamber regarding the general path and dispersion of the fog.

The fog dispersed evenly throughout the bin within 3-5 minutes and large, slow swirling eddies were observed. Small stagnant zone occurred only in the corners of the bin. As fresh air was drawn in the rear of the chamber the fog cleared slowly from the 
back of the bin to the front, and did so evenly on a vertical plane. The initial evaluation displayed a fairly even flow distribution, adequate internal mixing, and a consistent air exchange rate.

Mass Balance/Recovery Test. A simple mass balance was conducted to assess the efficiency of the flux chamber and the integrity of the sampling system. The test was performed similarly to the recovery tests performed by Osada and Fukumoto (2001). A span gas mixture of $\mathrm{SO}_{2}$ and air was released into an empty bin by placing the span gas cylinder inside the bin and a constant emission rate was generated using a two-stage gas regulator and a variable flow rotameter. Equation 1 was used to determine the emission rate using the exhaust flow rate and the detected concentration of the analyzer. This emission rate was compared to the emission rate produced in the flux chamber. The recovery was determined using Eq. 2:

$$
R=\frac{E_{x}}{E_{\text {std }}} \times 100 \%
$$

Where $E_{x}$ is the calculated emission rate $(\mathrm{g} / \mathrm{s})$ determined using equation $1, E_{\text {std }}$ is the emission rate $(\mathrm{g} / \mathrm{s})$ released inside the chamber and $R$ is the recovery (\%) of the mass balance. Eleven recovery tests were performed for a range of exhaust flow rates. The varied flow rates will assist in determining an optimal flow rate for this particular system.

Flow Sensitivity Test. It is important to optimize the velocity or air exchange rate of the dynamic system to simulate natural conditions. If velocities are too high across the pile overestimates may occur by creating a pressure deficit between the compost and air (Reichman and Rolston, 2002), pulling emissions from the pore spaces. As well, if the 
air exchange rate is too high, dilution may become a problem depending on the sensitivity of the analyzer. If the air exchange rate is not great enough, however, the concentration may build up and impede the emission rate form the pile leading to underestimation of the emission rates.

The amount of time required to reach steady state and stable concentration measurements as well as the change in emission rate was evaluated by sampling one pile at various flow rates. Flow rates were varied from 60 to $136 \mathrm{~m}^{3} / \mathrm{h}$, which resulted in a velocity across the pile between 0.0086 and $0.0254 \mathrm{~m} / \mathrm{s}$ and an air exchange rate between 12.75 and 37.5 exchanges per hour.

\section{RESULTS \& DISCUSSION}

During the first compost trial (SW_O1) the location, of the thermocouples were varied horizontally as well as vertically from the center of the pile to within $0.61 \mathrm{~m}$ from the edge of the pile. The positions of the thermocouples were not change for the entire primary stage of the compost cycle. Temperature profiles seemed to vary mainly with depth and the horizontal location made little difference. Therefore, thermocouples were kept horizontally in the center of the bin and only varied with height for all subsequent trials.

Temperature profiles are shown in Fig. 4 for SW_01. During the first 90 days (primary stage), temperatures throughout the pile rose quickly, peaked at $65^{\circ} \mathrm{C}$ and slowly decreased. Temperatures remained above $55^{\circ} \mathrm{C}$ for at least 10 days in all areas but longer for the lower regions. This allowed sufficient time for the kill-off of pathogenic microbes. The pile settled a substantial amount $(0.5 \mathrm{~m})$ during this period of high aerobic 
activity. The vertical dashed lines in Fig. 4 indicate days in which the pile was mechanically turned with a front-end loader to reintroduce air and promote aerobic decomposition. During the first turning period, most of the soft tissue was degraded and the mixture consisted of mainly large bones (skulls and femurs) and hair. Even fewer carcass remains were visible at the next 2 turning periods, mainly in the form of brittle bone fragments. The woodchips used in the pile did not show external signs of extensive decomposition. The woodchips, however, were darker in appearance and the particle size was reduced but the transformation into a dark humus material did not occur as typically reported for finished compost. This result is likely due to the high lignin content in wood along with the larger woodchip fragments, which provide less surface area for the microbes compared to other carbon bulking agents such as sawdust.

The second and third swine piles (SW_02 \& SW_03) were constructed during cold ambient temperatures. In both trials the swine carcasses were refrigerated at $4^{\circ} \mathrm{C}$ for approximately one week prior to composting. Due to the combination of cold carcasses and cold ambient conditions the microbial activity in both piles was inhibited. Pile temperatures remained below $10^{\circ} \mathrm{C}$ for 60 days in SW_02 and for 45 days in SW_03. These results were inconsistent with the rapid temperature increase seen in SW_01, which was initiated the same day the swine were euthanized. Leachate from SW_02 and SW_03 was observed once the pile temperatures began to raise. There was no leachate observed during the SW_01 trial.

The construction of the companion animal pile was slightly different than the other piles. Since the quantity of animal mortalities in a single day was not great enough to fill the entire bin, the pile was constructed over a period of 23 days, about 1 layer per 
week. As each layer was added to the pile, the temperature profiles, given in Fig. 5, changed accordingly. The bottom or first layer temperature began to steadily rise within a few days into the trial. When the next layer was added the temperature on the bottom layer was suppressed and fell to a steady temperature around $33^{\circ} \mathrm{C}$. The same suppression of temperature in the middle layer was observed once the final layer was added to the pile. The top layer was the only layer to rise above $50^{\circ} \mathrm{C}$ in the primary phase shown. Each time a layer was added, the oxygen level in the lower layers was consumed quickly and could not replenish due to compression of the pile. Ultimately, the pore space available for air was reduced indicating anaerobic activity was likely dominating in the lower layers of the pile.

Poultry compost trials, PO_01 and PO_02, commenced on the same day. The temperature profiles for both trials followed the same trend. Temperatures near the top of the pile increased rapidly to greater than $55^{\circ} \mathrm{C}$ as shown in Fig. 6 for PO_02. The temperature profile of the pile was similar to the $\mathrm{CO}_{-} 01$ trial where temperatures were high at the top of the pile and decreased with depth. This suggests high aerobic activity occurred at the top of the pile and became more anaerobic with depth. The difference between the poultry and the first swine pile was the size of the carcasses. There were fewer swine carcasses at a much larger unit mass per carcass compared to the poultry. The larger swine allowed for greater space between carcasses in each layer. The porous space for airflow around the swine carcasses was much greater than that for the poultry carcasses, which created conditions more favourable for aerobic decomposition.

\section{Mass Balance/Recovery}


Emission recovery results indicated that the dynamic chamber achieved recoveries between 44.6 and $91.9 \%$ depending on the positioning of the emission source and the exhaust flow rate. Figure 7 displays the emission rate recoveries based on the number of air exchanges per hour in the headspace of the chamber. For the first set of trials the emission rate was generated at the back of the flux chamber at a rate of $8.5 \mu \mathrm{g} / \mathrm{s} \mathrm{(Fig.} 7 \mathrm{a}$ ). Duplicate trials for each air exchange rate were performed over a period of 2 days. Emission recoveries were exceptionally lower for 4.3 air exchanges per hour than for any of the higher exchange rates. This could be due to insufficient mixing of $\mathrm{SO}_{2}$ throughout the chamber headspace. A higher recovery at this exchange rate may be achieved if the trial period was lengthened. Once the exchange rate was $\geq 8.9$, the percent recovered remained fairly consistent.

Figure $7 \mathrm{~b}$ displays the second set of trials that were performed with the emission source close to the front of the chamber and a higher generated emission rate $(42.3 \mu \mathrm{g} / \mathrm{s})$. The recoveries remained fairly constant over the entire range of exchange rates ranging from 86.2 to $91.9 \%$ for 4.1 to 11.7 air exchanges per hour. Moving the emission source closer to the front of the bin provided a more direct route to the exhaust stream and not as much mixing, thus providing a higher recovery for 4.1 exchanges in the second set of trials. However, when the exchange rates were $\geq 8.9$ exchanges, the placement of the emission sources made little difference.

The error bars shown in Fig. 7 account for some of the uncertainties associated with collecting a sample of the mass released. These uncertainties include 1) the measurement of the exhaust flow rate $( \pm 5 \%), 2)$ the rotameter used to generate a known emission rate ( $\pm 2 \%$ of displayed value), and 3$)$ the analyzer error due to water vapour 
interference (- $3 \%$ of reading). There are other uncertainties that cannot be directly accounted for such as adsorption or diffusion of $\mathrm{SO}_{2}$ into the concrete walls.

\section{Flow sensitivity}

Flow sensitivity tests were performed for $\mathrm{CO}_{2}, \mathrm{NH}_{3}$ and $\mathrm{CH}_{4}$ over the second poultry pile (PO_02). Three separate flow rates were tested spanning the entire range of the blower. In each case the concentrations reached a fairly steady value within 5 minutes of sampling. The comparison of the change in concentration and emission rate is shown in Table 3. As the flow is increased the concentration detected decreased and the estimated emission rate increased. For the range of flow rates tested only a near linear relationship was observed for both the concentration and the emission rate. The decrease in concentration for each of the gases occurred at a much steeper rate than the rate of increase of the corresponding emission rate. The numbers do suggest that there was a slight convergence of the emission rate when the flow increased from trial 1 to trial 3. However, the range of flows was not sufficient enough to determine an optimal air exchange rate. Also, as the flow increased the percent increase of the estimated emission rates depended on the gas being analyzed suggesting that an optimal velocity across the

pile may depend on the diffusive properties of the individual compounds. Further testing will need to be conducted to collect more data points and determine an optimal air exchange rate. Longer trials (over a period of days) and a higher range of flows would provide the necessary information needed to optimize the design air exchange rate.

\section{CONCLUSIONS}


Preliminary results for this study show that composting is an effective method for animal mortality disposal. Almost no remains were found after a complete cycle composting swine mortalities. During the primary stages of composting companion animals and poultry the temperatures were cooler near the bottom layers, unlike the first swine pile where the temperature profile was more evenly distributed. This result is attributed to the amount of space left between the carcasses on a given layer, which was much greater for SW_01 than the subsequent trials. Staged construction of the CO_01 pile compressed the bottom layers and restricted the oxygen levels as well and thus resulted in cooler lower layer temperatures.

Composting animal mortalities after they had been cooled for a significant period and in a cold climate proved challenging since microbial activity was severely inhibited thus extending the time required to compost. Temperature increases were not observed until 60 and 45 days from the start of the trials for SW_02 and SW_03 respectively.

Overall the performance of the flux chamber design displayed promising results regarding flow patterns. Steady conditions were obtained in a reasonably short period (less than 5 minutes) and internal mixing conditions were good. Air exchange patterns showed that the chamber headspace was completely exchanged and no stagnant fog remained after one full air exchange. Emission mass balance tests showed that recoveries up to $91.9 \%$ could be achieved in the flux chamber and collection system. Recoveries were higher for air exchange rates of 8.9 and greater. The degree of which the $\mathrm{SO}_{2}$ adsorbs to concrete or diffuses into the walls is unknown and could account for part of the slight underestimations. 
Emissions of $\mathrm{CH}_{4}, \mathrm{NH}_{3}$, and $\mathrm{CO}_{2}$ were detected over the second poultry pile (see Table 3). Increasing the flow rate through the flux chamber showed an increase of the estimated emission rate. The extent of the increased emission rate seemed to depend on the gaseous compound suggesting diffusive properties of the gases play a role in the convergence to a steady emission rate. The range of flows was not too small to see the convergence of the emission rates. Further testing is required to fully quantify the emission characterization system. Extended sampling periods, a wider range of flow rates, and recovery tests for different gases will assist in determining the optimal operating conditions of the flux chamber.

\section{Acknowledgements}

The authors gratefully acknowledge the financial and other contributions for this project from Environment Canada, Ontario Ministry of Agriculture, Food, and Rural Affairs, Ontario Ministry of the Environment, Ontario Pork, and the University of Guelph. Special thanks are also extended to R. Ford, J. Rykes, and M. Thomson for their technical assistance. 


\section{REFERENCES:}

Amon, B., Th. Amon, Ch. Alt. 2001. Emissions of $\mathrm{NH}_{3}, \mathrm{~N}_{2} \mathrm{O}$ and $\mathrm{CH}_{4}$ from dairy cows housed in a farmyard manure tying stall (housing, manure storage, manure spreading). Nutrient Cycling and Agroecosystems 60:103-113.

Beck-Friis, B., S. Smars, H. Jonsson H. Kirchmann. 2001. Gaseous emissions of carbon dioxide, ammonia and nitrous oxide from organic household waste in a compost reactor under different temperature regimes. Journal of Agricultural Engineering Resources 78:4:423-430.

Draper, D. 2002. Our Environment: A Canadian Perspective, $2^{\text {nd }}$ ed. Scarborough, ON: Nelson Thomas Learning.

Glanville, T. D. 1999. Composting dead livestock: a new solution to an old problem. Livestock Industry Facilities \& Environment, Leopold Center. Iowa State University, Department of Agriculture \& Biosystems Engineering.

Guenther, A., C. Geron, T. Pierce, B. Lamb, P. Harley, R. Fall. 1999. Natural emissions of non-methane volatile organic compounds, carbon monoxide, and oxides of nitrogen from North America. Atmospheric Environment 34:22052230 .

Hao, X., C. Chang, F.J. Larney. 2004. Carbon, nitrogen balances and greenhouse gas emission during cattle feedlot manure composting. Journal of Environmental Quality 33:37-44.

Hao, X., C. Chang, F.J. Larney, G.R. Travis. 2001. Greenhouse gas emissions during cattle feedlot manure composting. Journal of Environmental Quality 30:376386.

Hartman, B., 2003. How to collect reliable soil-gas data for upward risk assessments: part 2: surface flux-chamber method. LUSTLine bulletin 44, 14-28, CA.

Keener, H.M., D.L. Elwell, M.J. Monnin. 2000. Procedures and equations for sizing of structures and windrows for composting animal mortalities. Applied Engineering in Agriculture 16:6:681-692.

Kuroda, K, T. Osada, M. Yonage, A. Kanematu, T. Nitta, S. Mouri, T. Kojima. 1996. Emissions of malodorous compounds and greenhouse gases from composting swine feces. Bioresource Technology 56:265-271.

Martins, O. and T. Dewes. 1992. Loss of nitrogenous compounds during composting of animal wastes. Bioresource Technology 42:103-111. 
Morse, D.E. 2001. Composting animal mortalities. Agricultural Development Division: Minnesota Department of Agriculture. St. Paul, MN.

Noble, R. and R.H. Gaze. 1995. Preparation of mushroom (agaricus bisporus) composts in controlled environments: factors influencing compost bulk density and productivity. International Biodeterioration and Biodegradation 93-100.

Koebel, G,. A. Rafail, J. Morris. 2003. On-farm composting of livestock and poultry. Ontario Ministry of Agriculture and Food (OMAF) Fact Sheet.

Osada, T., and Y. Fukumoto. 2001. Development of a new dynamic chamber system for measuring harmful gas emissions from composting. Water Science and Technology 44:9:79-86.

Paillat, JM., P. Robin, M. Hassouna, P. Leterme. 2005. Predicting ammonia and carbon dioxide emissions from carbon and nitrogen biodegradability during animal waste composting. Atmospheric Environment 39:6833-6842.

Parkinson, R., P. Gibbs, S. Burchett, T. Misselbrook. 2004. Effect of turning regime and seasonal weather conditions on nitrogen and phosphorous losses during aerobic composting. Bioresource Technology 91:171-178.

Reichman, R. and D.E. Rolston. 2002. Atmospheric pollutants and trace gases: design and performance of a dynamic gas flux chamber. Journal of Environmental Quality 31:1774-1781.

Smet, E., H. Van Langenhove, I. De Bo.1999. The emission of volatile compounds during the aerobic and the combined anaerobic/aerobic composting of biowaste. Atmospheric Environment 33:1295-1303.

Sommer, S.G. and H.B. Moller. 2000. Emission of greenhouse gases during composting of deep litter from pig production - effect of straw content. Journal of Agricultural Science 134:327-335.

Thompson, A.G., C. Wagner-Riddle, R. Fleming. 2004. Emissions of $\mathrm{n}_{2} \mathrm{O}$ and $\mathrm{ch}_{4}$ during the composting of liquid swine manure. Environmental Monitoring and Assessment 91:87-104. 


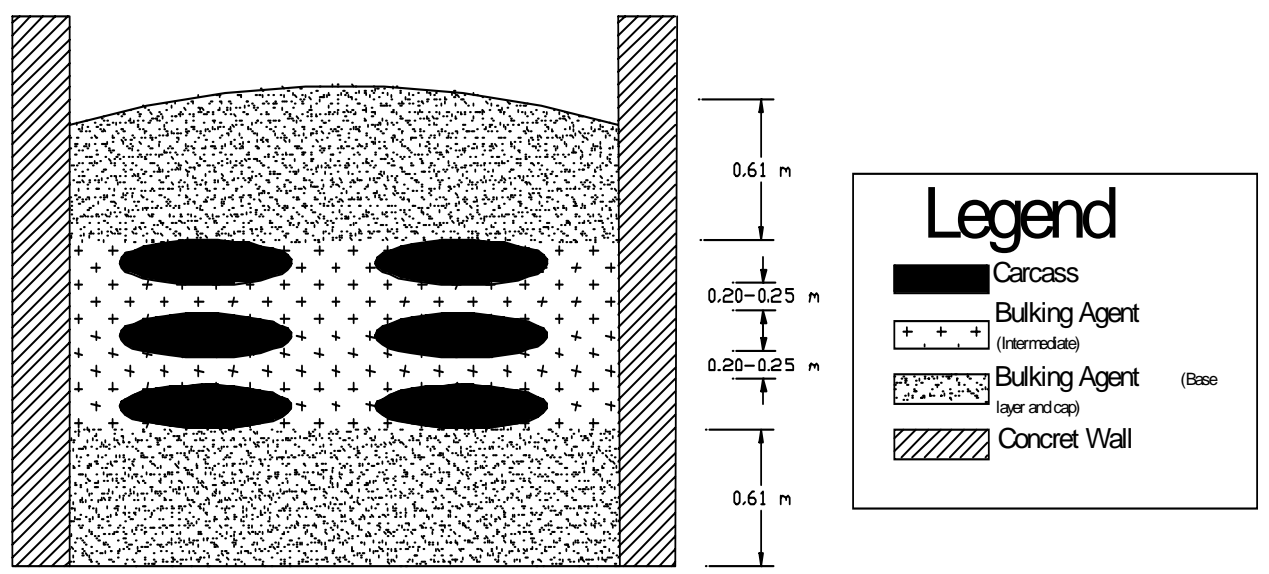

Figure 1: Cross-sectional view of the constructed deadstock compost pile in a bin. Note that the bulking agent used to add the base and the cap was the same as the intermediate bulking agent.

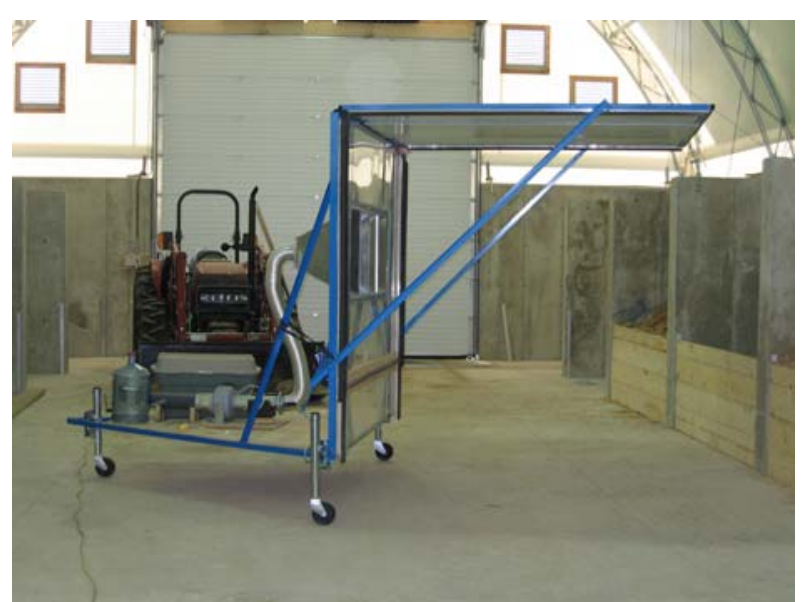

Figure 2: Photograph of the dynamic flux chamber. The chamber is able to move from bin to bin by rolling and adjusting the height of the wheel jacks. 


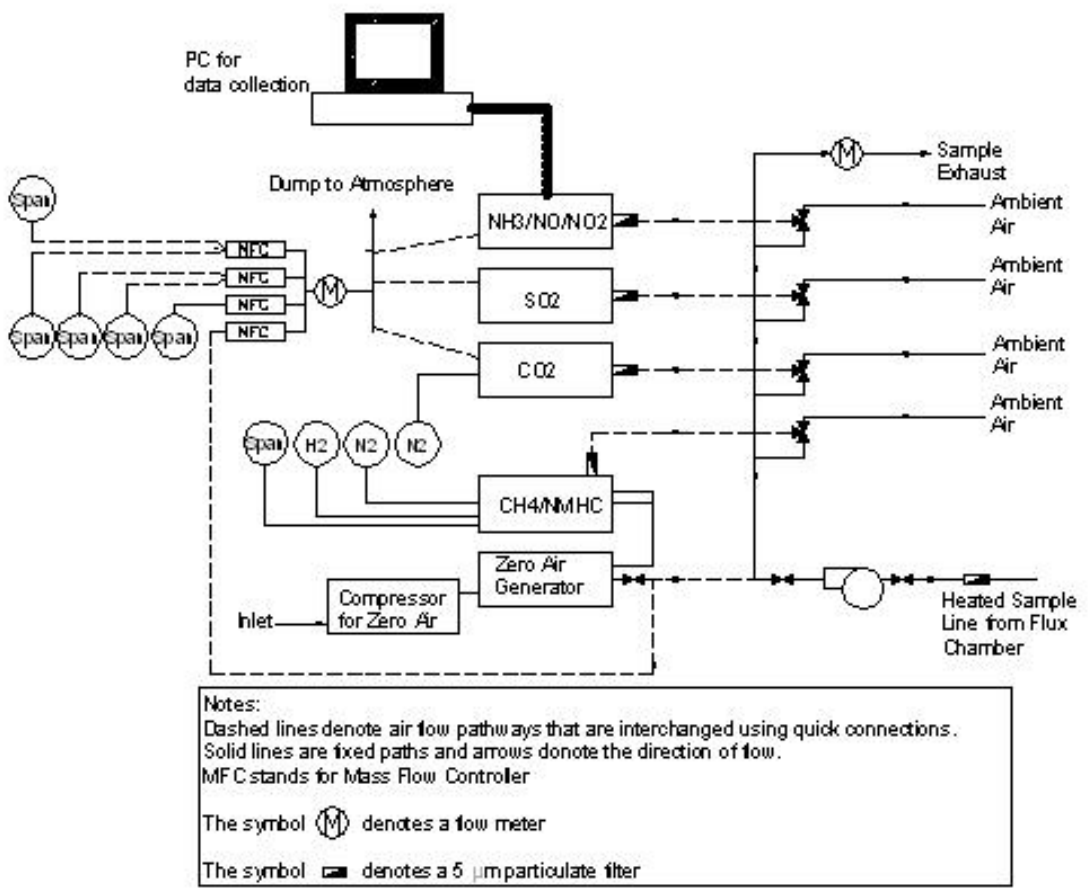

Figure 3: Process flow diagram of the emission analysis setup.

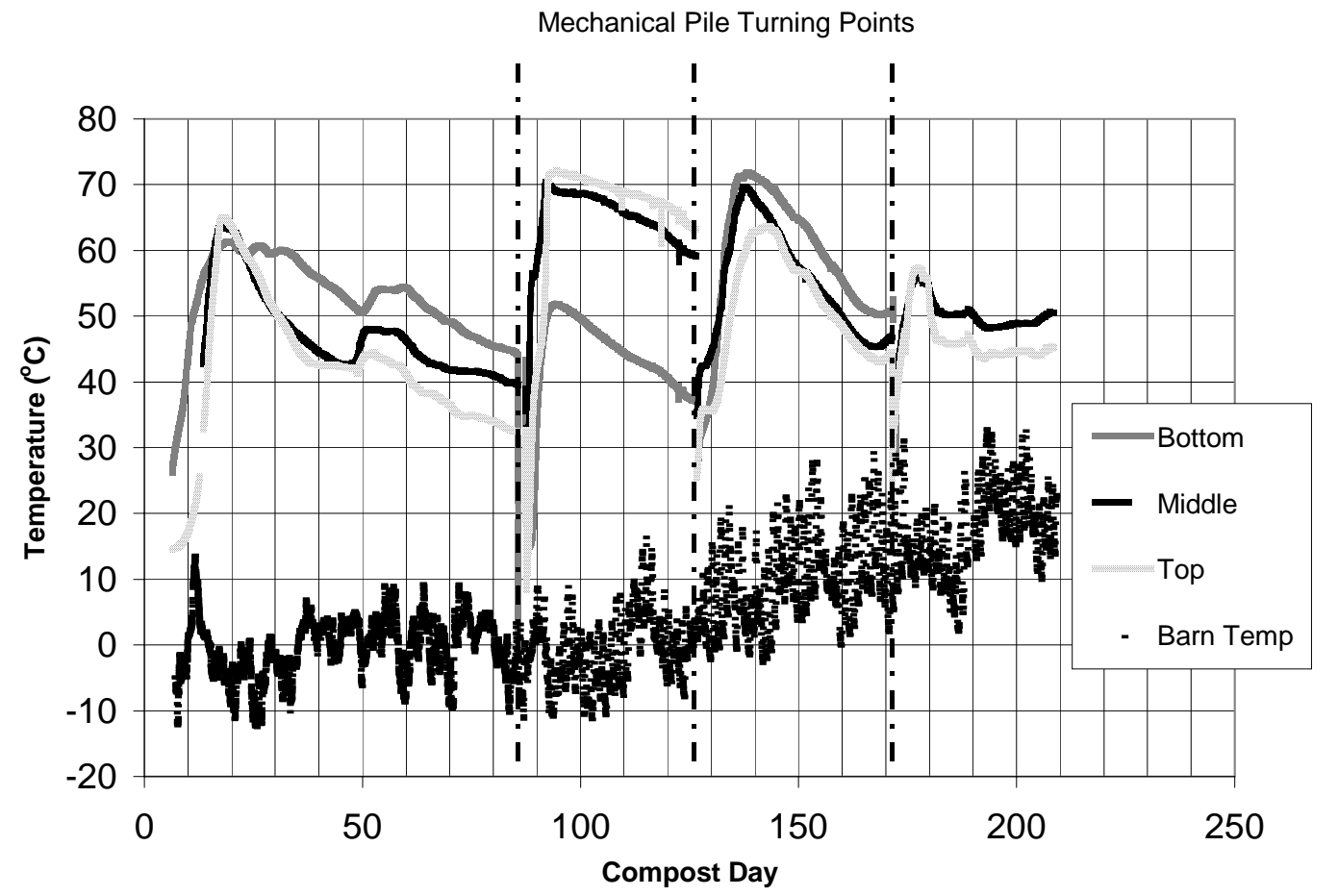

Figure 4: Compost temperatures for a complete compost cycle (SW_01) 


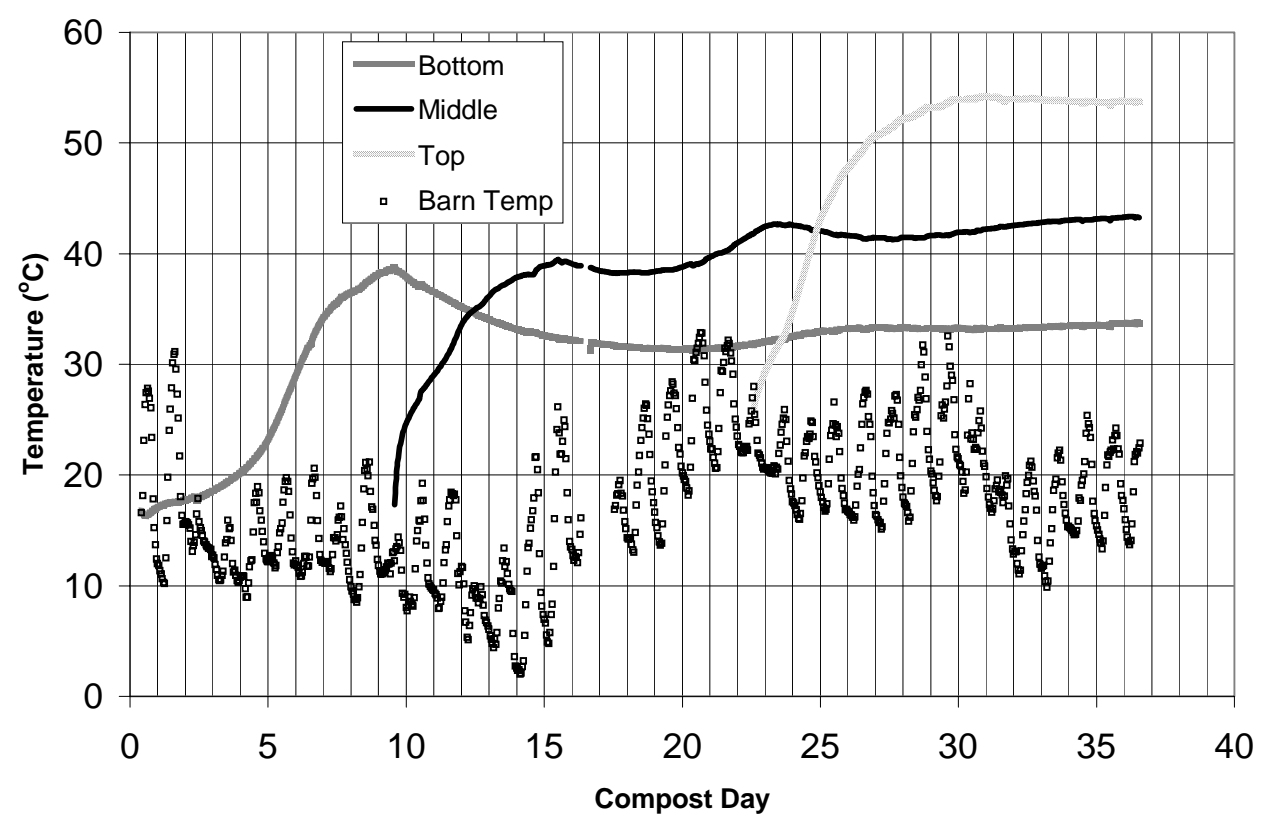

Figure 5: Temperatures for the first 37 days of compost trial CO_01.

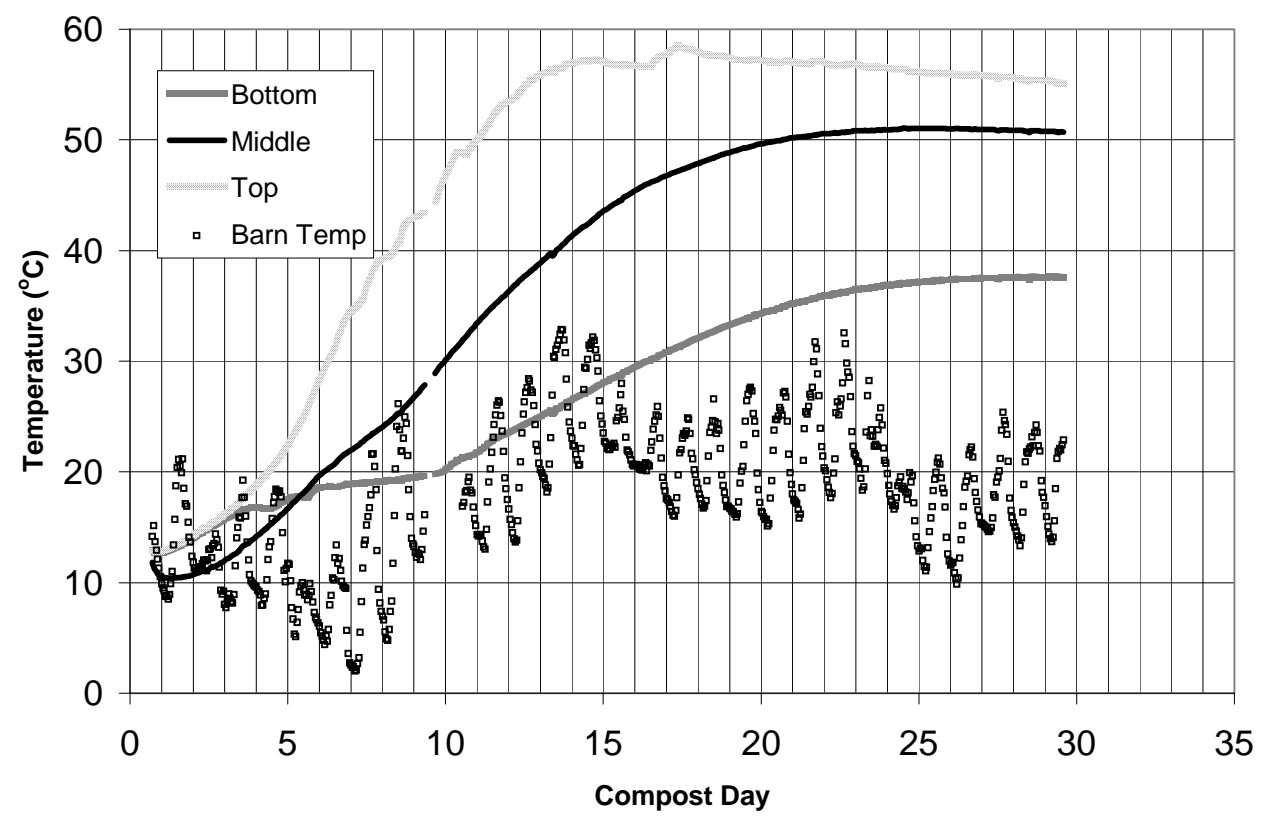

Figure 6: Temperatures for the primary stage of compost trial PO_02. 


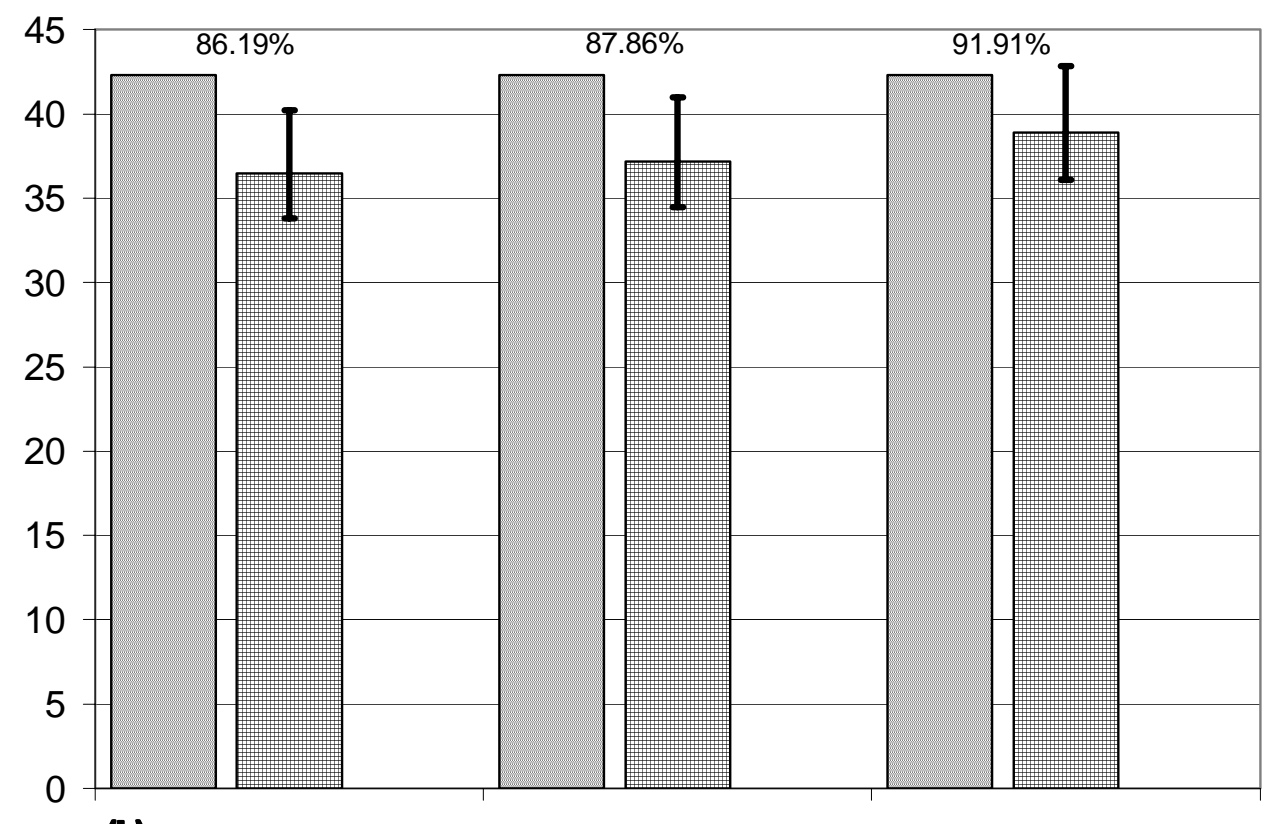
(b)
4.1
8.1
11.7

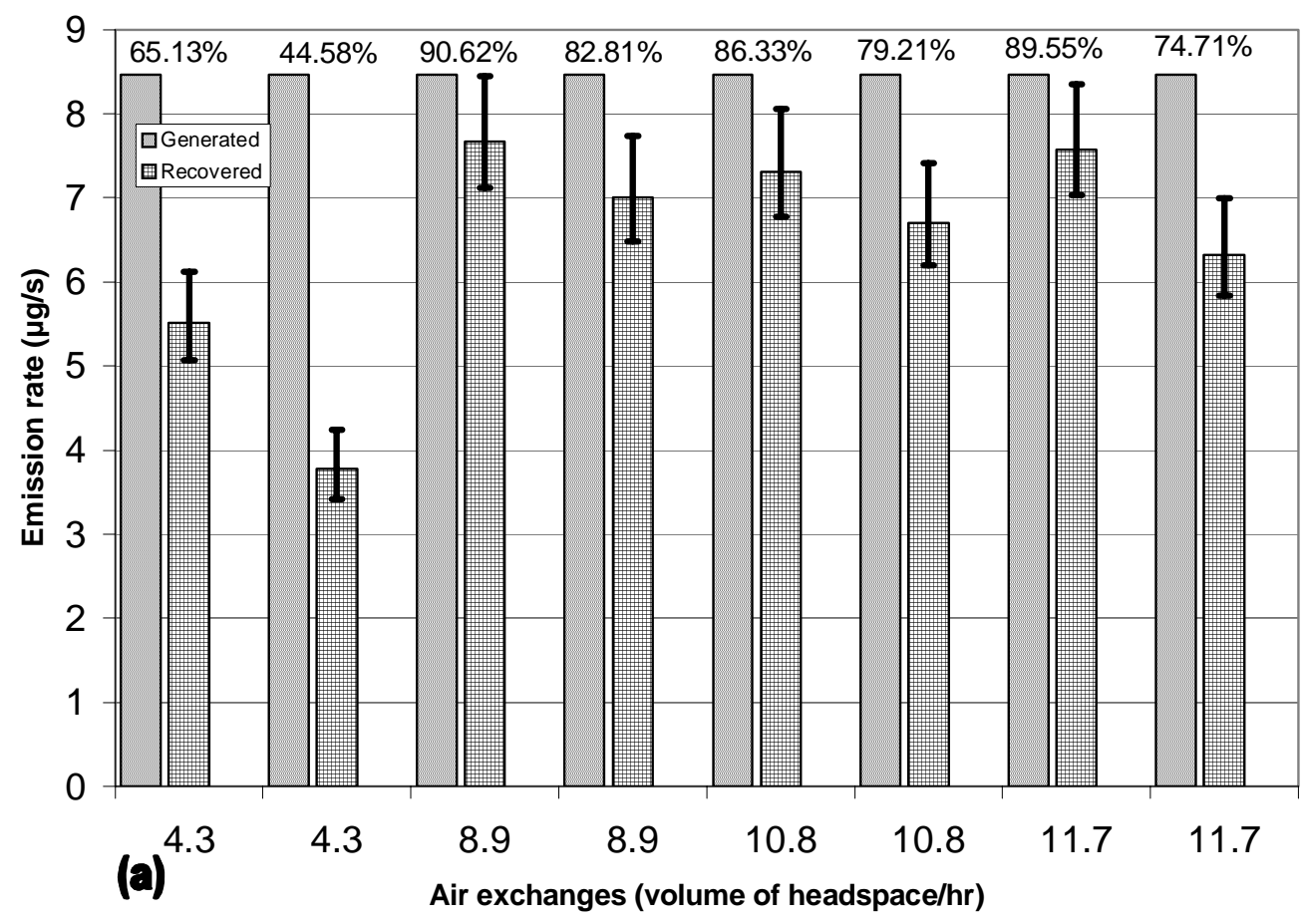

Figure 7: Recovery test results and relative error bars for a) an emission generation rate of $8.5 \mu \mathrm{g} / \mathrm{s}$ (bottom graph) and b) an emission generation rate of $42.3 \mathrm{\mu g} / \mathrm{s}$ (top graph). 
Table 1: The initial properties for six compost trials. Each pile is specific to one type of species and sawdust was used as a bulking agent.

\begin{tabular}{cccccccc}
\hline $\begin{array}{c}\text { Compost } \\
\text { Trial Start } \\
\text { Dates }\end{array}$ & $\begin{array}{c}\text { Control } \\
\text { Number }\end{array}$ & Species & $\begin{array}{c}\text { Mass } \\
\mathbf{( k g )}\end{array}$ & $\begin{array}{c}\text { Number } \\
\text { of } \\
\text { Layers }\end{array}$ & $\begin{array}{c}\text { Mass of* } \\
\text { Bulking Agent } \\
\mathbf{( k g )}\end{array}$ & $\begin{array}{c}\text { Initial**} \\
\text { Moisture } \\
(\%)\end{array}$ & $\begin{array}{c}\text { Initial*** } \\
\text { C:N }\end{array}$ \\
\hline 18-Nov-05 & SW_01 & Swine & 790 & 2 & 2721 & 70.4 & 26 \\
\hline 9-Feb-06 & SW_02 & Swine & 1000 & 3 & 2895 & 70.5 & 23 \\
\hline 16-Mar-06 & SW_03 & Swine & 1055 & 3 & 2895 & 70.6 & 22 \\
\hline 9-May-06 & CO_01 & $\begin{array}{c}\text { Canine } \\
\text { \& Feline }\end{array}$ & 730 & 4 & 3254 & 70.1 & 32 \\
\hline 16-May-06 & PO_01 & $\begin{array}{c}\text { Broiler } \\
\text { Turkey }\end{array}$ & 850 & 5 & 3265 & 68.2 & 25 \\
\hline 16-May-06 & PO_02 & $\begin{array}{c}\text { Broiler } \\
\text { Turkey }\end{array}$ & 660 & 5 & 3265 & 68.3 & 29 \\
\hline
\end{tabular}

* The mass of the bulking agent was estimated using the volume and bulk density.

** Calculated on a mass basis.

*** Calculated on a dry mass basis. The moisture contents, $\mathrm{C}: \mathrm{N}$ ratios, and densities were obtained from Keener et al. (2000).

Table 2: General properties of the continuous emission analyzers.

\begin{tabular}{cccc}
\hline TEC Model & Gas & Range (ppm) & Detection Limit \\
\hline $17 \mathrm{C}$ & $\mathrm{NH}_{3} / \mathrm{NO} / \mathrm{NO}_{2}$ & $0-100$ & $1 \mathrm{ppb}$ \\
\hline $55 \mathrm{C}$ & $\mathrm{CH}_{4} / \mathrm{NMHC}$ & $0-2000$ & $20 \mathrm{ppb} \mathrm{CH4,50} \mathrm{ppb}$ \\
& $\mathrm{SO}_{2}$ & $0-10$ & $0.1 \mathrm{ppb}$ \\
\hline $43 \mathrm{C}$ & $\mathrm{CO}_{2}$ & $0-5000$ & $1 \mathrm{ppm}$ \\
\hline $41 \mathrm{i}$ & &
\end{tabular}


Table 3: The concentrations and emissions rates of $\mathrm{CH}_{4}, \mathrm{NH}_{3}$, and $\mathrm{CO}_{2}$ for three separate flow rates over compost trial PO 02 .

\begin{tabular}{|c|c|c|c|c|c|}
\hline \multirow{2}{*}{ Trial Number } & \multirow{2}{*}{$\begin{array}{c}\text { Flow Rate } \\
\left(\mathrm{m}^{3} / \mathrm{min}\right)\end{array}$} & \multicolumn{4}{|c|}{ Methane } \\
\hline & & Mean & SD & $\mathbf{n}$ & $\mathrm{CV}$ \\
\hline \multicolumn{6}{|l|}{ Concentrating ppm } \\
\hline Trail 1 & 0.99 & 49.05 & 2.67 & 33 & 0.05 \\
\hline Trial 2 & 1.70 & 32.68 & 1.79 & 35 & 0.05 \\
\hline Trial 3 & 2.27 & 26.06 & 1.31 & 21 & 0.05 \\
\hline \multicolumn{6}{|l|}{$\begin{array}{l}\text { Emission Rate } \\
\text { (mg/s) }\end{array}$} \\
\hline Trail 1 & 0.99 & 0.54 & 0.03 & 28 & 0.05 \\
\hline Trial 2 & 1.70 & 0.60 & 0.03 & 30 & 0.05 \\
\hline Trial 3 & 2.27 & 0.64 & 0.03 & 16 & 0.04 \\
\hline Concentrating ppm & & \multicolumn{4}{|c|}{ Ammonia } \\
\hline Trail 1 & 0.99 & 3.49 & 0.21 & 31 & 0.06 \\
\hline Trial 2 & 1.70 & 3.16 & 0.06 & 39 & 0.02 \\
\hline Trial 3 & 2.27 & 2.76 & 0.09 & 51 & 0.03 \\
\hline \multicolumn{6}{|l|}{$\begin{array}{l}\text { Emission Rate } \\
(\mathrm{mg} / \mathrm{s})\end{array}$} \\
\hline Trail 1 & 0.99 & 0.040 & 0.002 & 31 & 0.059 \\
\hline Trial 2 & 1.70 & 0.062 & 0.001 & 39 & 0.019 \\
\hline Trial 3 & 2.27 & 0.072 & 0.002 & 51 & 0.031 \\
\hline Concentrating ppm & & \multicolumn{4}{|c|}{ Carbon Dioxide } \\
\hline Trail 1 & 0.99 & 920.85 & 47.48 & 60 & 0.05 \\
\hline Trial 2 & 1.70 & 821.96 & 12.97 & 43 & 0.02 \\
\hline Trial 3 & 2.27 & 775.25 & 32.10 & 55 & 0.04 \\
\hline \multicolumn{6}{|l|}{$\begin{array}{l}\text { Emission Rate } \\
(\mathrm{mg} / \mathrm{s})\end{array}$} \\
\hline Trail 1 & 0.99 & 27.37 & 1.41 & 60 & 0.05 \\
\hline Trial 2 & 1.70 & 41.88 & 0.66 & 43 & 0.02 \\
\hline Trial 3 & 2.27 & 52.67 & 2.18 & 55 & 0.04 \\
\hline
\end{tabular}




\section{Table of figures}

Figure 1: Cross-sectional view of the constructed deadstock compost pile in a bin. Note that the bulking agent used to add the base and the cap was the same as the intermediate

bulking agent.

Figure 2: Photograph of the dynamic flux chamber. The chamber is able to move from

bin to bin by rolling and adjusting the height of the wheel jacks................................... 22

Figure 3: Process flow diagram of the emission analysis setup...................................... 23

Figure 4: Compost temperatures for a complete compost cycle (SW_01) ....................... 23

Figure 5: Temperatures for the first 37 days of compost trial CO_01............................ 24

Figure 6: Temperatures for the primary stage of compost trial PO_02 ........................... 24

Figure 7: Recovery test results and relative error bars for a) an emission generation rate

of $8.5 \mathrm{ug} / \mathrm{s}$ (bottom graph) and b) an emission generation rate of $42.3 \mu \mathrm{g} / \mathrm{s}$ (top graph). 25 